Pensamiento Crítico No. 7, pág. 85 - 95

\title{
Marco Teórico de la Incidencia de la Expansión Monetaria en las Tasas de Interés y los Ciclos Económicos Perú 1990-2006. Primeros Hallazgos Pablo Rivas Santos
}

Palabras claves: Mercado de dinero, expansión crediticia, tasas de interés de mercado y relación monetaria.

Resumen : Que la gente, después de la inflación, sea más pobre que antes de la inflación depende de circunstancias particulares de cada caso. La teoría monetaria, al afirmar que la expansión crediticia inorganica, destaca que los consumidores, al sufrir la expansión crediticia, se empobrecen en comparación a las satisfacciones que habrían disfrutado de no haberse producido esa expansión crediticia. En Perú, los períodos Agosto 1974 - Julio 1976; Enero 1980 - Diciembre 1982; y Julio 1985 - Diciembre 1987 registraron un continuo progreso económico, un continuo incremento de las disponibilidades de bienes de capital y un alza continuo del nivel de vida. Ese progreso económico se produjo a un ritmo tan rápido que muchas veces logró compensar y superar las pérdidas provocadas por el excesivo consumo y las desacertadas inversiones de la expansión crediticia. En tales casos, el sistema económico peruano gozó, después del auge, de mayor prosperidad que antes de producirse tal auge; sin embargo, la gente se consideraba empobrecida, al darse cuenta de las enormes posibilidades de mayor prosperidad aún, que han sido debilitadas y desperdiciadas.

La continua alza de la actividad económica y la inevitable secuencia de los auges son efectos provocados por los reiterados intentos de rebajar las tasas de interés del mercado mediante la expansión crediticia. No hay forma de evitar el colapso final de todo auge desatado a base de expansión crediticia. Tan solo cabe optar entre provocar más pronto la crisis poniendo fin voluntariamente a la expansión crediticia o dejar que, por sí solos, el desastre y la ruina total del sistema monetario se produzcan un poco mas tarde. 


\section{Pablo Rivas Santos}

De la desastrosa situación en que termina el auge; sólo se puede salir produciendo nuevos ahorros y con ellos los bienes de capital que permitan aprovisionar armoniosamente a todos los sectores productivos; pasando así a un mercado en el cual la progresiva acumulación de capital garantizará la continua elevación del nivel de vida de los consumidores. Es necesario aportar a aquellos sectores, (indebidamente desatendidos durante el auge) los bienes de capital que necesitan. Han de bajar los salarios nominales; la gente, temporalmente, habrá de reducir su consumo mientras se repone el capital dilapidado en torpes inversiones. Aquellos a quienes tan dolorosamente impresionan las inevitables penalidades del reajuste deberían cuidarse de impedir, a tiempo, toda expansión del crédito inorgánico.

\section{INTRODUCCIÓN}

El estudio de investigación “LA INCIDENCIA DE LA EXPANSIÓN MONETARIA EN LAS TASAS DE INTERÉS Y LOS CICLOS ECONÓMICOS PERÚ 1990-2006” tiene como objetivo contribuir con un instrumental analítico que permita dar una explicación monetaria de las variaciones de la tasa de interés y los ciclos económicos en la economía peruana período 1990-2006. Y en particular identificar los vacíos de las teorías monetarias clásicas y keynesiana sobre la incidencia de la expansión monetaria en las tasas de interés y los ciclos económicos para la economís peruana. Estimar la eficiencia de la explicación monetaria de los ciclos económicos de la economía peruana para mentener una moneda estable con un crecimiento sostenido de la producción. Establecer un nuevo enfoque para analizar la incidencia de la expansión monetaria en las tasas de interés y los ciclos económicos en la economía financiera peruana. Focalizar tasas de interés y magnitudes de los ciclos económicos que no desorganicen la economía financiera peruana.

El presente estudio permitirá verificar que las variaciones de las tasas de interés y los ciclos económicos de la economía peruana en el período 1990-2006 se deben en mayor medida a cambios en la cantidad de dinero que a perturbaciones fiscales y del exterior de país.

La incidencia de la expansión monetaria sobre las tasas de interés y los ciclos económicos tiene un marco teórico que se basa en el supuesto de la no simultaneidad ni proporcionalidad de las variaciones de las tasas de interés y la expansión monetaria; y el supuesto de que el valor es el reflejo del ansia con que la gente aspira las cosas que le apetece, por lo que la gente compra y vende, única y exclusivamente, por cuanto valoran en menos lo que dan que lo que reciben"

Haremos una comparación de los distintos marcos teóricos que analizan la incidencia de la expansión monetaria sobre la tasa de interés y los ciclos económicos, a fin de determinar cuál de esos marcos permiten ver en su exacta dimensión la mencionada incidencia. Así 
determinaremos el marco teórico idóneo bajo el cual se analiza la incidencia de la expansión monetaria en las tasas de interés y los ciclos económicos, de tal manera que permita diseñar eficaces políticas monetarias y crediticias que den solidez al sector financiero peruano.

Los resultados de la investigación tendrán diversos efectos científicos en el campo de la economía monetaria. Promoverá un sistema monetario que garantice una moneda estable. Promoverá un política monetaria orientada a tener una moneda con poder adquisitivo estable. Garantizará la eficacia de la política monetaria y crediticia peruana.

En la economía, los precios fluctúan; debiendo los empresarios acomodar sus actuaciones a tales fluctuaciones. Porque los empresarios prevén fluctuaciones y de estas fluctuaciones pretenden obtener ganancias, ellos se lanzan a actuaciones de mercado. Los empresarios más emprendedores y prudentes buscan ganancia personal readaptando continuamente la producción, para atender las necesidades que los consumidores ya sienten y conocen; como otras necesidades que todavía ni siquiera han advertido. Dichas actuaciones especulativas revolucionan diariamente la estructura de precios, provocando variaciones en las tasas de interés de mercado.

\section{EL COMPONENTE EMPRESARIAL DE LAS TASAS DE INTERÉS}

El prestamista es un empresario, porque la concesión de un préstamo es un acto empresarial y especulativo, cuyo futuro resultado -bueno o malo- es incierto. El prestamista sabe que puede perder la totalidad o parte del principal.

No existe plena seguridad en un préstamo. Deudor y acreedor pueden caer en insolvencia: las hipotecas y otras garantías aportadas pueden desvalorizarse. El acreedor: se convierte en socio del deudor; aparece como virtual copropietario de los bienes que asegura la operación. Cualquier cambio en el mercado que influya en el valor de esos bienes afecta al acreedor directa e inmediatamente. El acreedor se interesa en los cambios que registra el precio de esos bienes dados en garantía. El capital es necesario emplearlo e invertirlo acertadamente, para que produzca interés y el principal no se pierda. Sólo percibe interés de mercado; el prestamista que acertadamente concede préstamos. En ese caso, el interés originario que obtiene el prestamista está incluido en tal interés de mercado (incluyendo tal interés de mercado el componente empresarial). El interés originario es una magnitud; que solo nuestro pensamiento nos permite separar del interés de mercado percibido por el prestamista.

Los factores que condicionan el acto empresarial influyen en el componente empresarial: al acreedor le afectan las circunstancias legales e institucionales. Los pactos que 


\section{Pablo Rivas Santos}

permiten al acreedor proceder contra las garantías del deudor (si el deudor pierde el capital prestado) se amparan en instituciones y disposiciones legales. El acreedor corre menos riesgo de pérdida que el deudor; cuando hay un ordenamiento legal e institucional que otorga acción al acreedor contra la mora del deudor.

El componente empresarial se distingue entre préstamos de consumo y préstamos empresariales.

El préstamo de consumo permite al deudor gastar por adelantado previstos ingresos futuros.

El acreedor adquiere condición empresarial al adquirir derecho a una parte de esos previstos ingresos (es como si el acreedor se interesara en esos previstos ingresos que producían los negocios del deudor). Es incierto el buen fin de tales préstamos, pues jamás cabe una seguridad absoluta de la efectiva aparición de esos previstos ingresos.

El componente empresarial se distingue entre préstamos a privados y préstamos al gobierno. La incertidumbre de préstamos al gobierno está en el ignorado plazo de sobrevivencia de los poderes políticos. Los gobiernos son electoralmente derribados como el gobierno de 1980-1985; tal vez los gobiernos como el gobierno de 1985-1990 se nieguen pagar las deudas contraídas por sus predecesores.

Se ha señalado el fondo hasta cierto punto inmoral de toda deuda pública a largo plazo.

Sobre todo cobro aplazado pende el peligro de la intervención estatal. En el período 1963-1990, los deudores fueron incitados contra los acreedores. Para la gente, el acreedor, era el rico ocioso, mientras el deudor era el hombre pobre, pero trabajador. La gente odiaba al acreedor considerándolo explotador y se consideraba al deudor víctima de la opresión. La gente considera que las medidas estatales que reducen las pretensiones de los acreedores beneficia a la mayoría, perjudicándose tan sólo una minoría de acreedores. La gente no se da cuenta que ha cambiado la composición de las clases deudoras y acreedoras. En esta época de obligaciones y préstamos, banca múltiple y seguros de vida; los amplios grupos integrados por los pobres son los acreedores. En cambio, los ricos propietarios de acciones, industrias, inmuebles y haciendas son los deudores. Los electores al pedir expropiar a los acreedores ingenuamente van en contra de sus propios intereses. Con una opinión pública desorientada, le era difícil al prestamista protegerse contra las expropiatorias medidas estatales. Ello habría provocado un alza del componente empresarial del interés de mercado; si tales riesgos políticos: se juntaran al mercado de préstamos y no afectaran por igual a toda propiedad privada de factores de producción. En ese período, no existía inversión segura contra el peligro político de la expropiación. Por ello el prestamista no reducía sus riesgos al invertir su riqueza en negocios, dejando de hacer préstamos públicos y privados. 
Los riesgos políticos (implícitos en el préstamo) influyen en el componente empresarial del interés de mercado. En el período 1985-1990 (cuando se preveía la eliminación de todos los pagos aplazados) el componente empresarial se incrementó exageradamente.

\section{LA COMPENSACIÓN POR LAS VARIACIONES DE PRECIOS}

\section{En la economía solo existe una tendencia que apunta hacia un final interés originario. Antes que se alcance tal final interés, la constante variación de circunstancias del mercado desvía el movimiento del interés que pasa a tender hacia otro final interés.}

En la economía, los precios fluctúan; debiendo los empresarios acomodar sus actuaciones a tales fluctuaciones. Porque los empresarios prevén fluctuaciones y de estas fluctuaciones pretenden obtener ganancias, ellos se lanzan a actuaciones de mercado. Los empresarios más emprendedores y prudentes buscan ganancia personal readaptando continuamente la producción, para atender las necesidades que los consumidores ya sienten y conocen; como otras necesidades que todavía ni siquiera han advertido. Dichas actuaciones especulativas revolucionan diariamente la estructura de precios, provocando variaciones del interés de mercado.

El empresario que prevé el alza de determinados precios aparece buscando préstamos en el mercado; dispuesto a pagar mayores intereses que los intereses que pagaría en el caso de prever una menor alza de precios.

El prestamista que prevé el alza de determinados precios, sólo otorga préstamos si el interés de mercado sube por encima del interés del mercado que prevalecía en una situación en la que se preveía una menor alza de precios.

Al empresario no le asusta ese mayor interés de mercado si considera su proyecto de tal rentabilidad que supone podrá soportar ese mayor interés de mercado. Tal prevista alza de precios desata una tendencia alcista del interés de mercado. Al variar la relación monetaria como en 1963-1992, previéndose una alza de precios; una de las opuestas tendencias prevalece. Entonces, se incorpora (en toda transacción donde hay pagos aplazados) una compensación por alza de precios.

La compensación por alza de precios la engendra la propia idea que los individuos se formen: del futuro; y de los cálculos que esos individuos se formulen partiendo de la correspondiente base. La compensación por alza de precios va paulatinamente tomando 


\section{Pablo Rivas Santos}

cuerpo, a medida que, primero, unos pocos individuos y, después, un número, cada vez mayor de individuos; advierten que el mercado se halla bajo los efectos de una variación de origen dinerario en la relación monetaria, variación que ha desatado específica tendencia en los precios. Sólo cuando los individuos comienzan (amparadas en esa tendencia) a comprar con la finalidad de ganar, se materializa la compensación por el alza de precios.

La compensación por el alza de precios: surge al amparo de consideraciones relacionadas a cambios previstos de la relación monetaria; la engendra: (en caso de suponerse el mantenimiento de tendencias inflacionistas) las primeras manifestaciones de ese fenómeno que luego, al generalizarse, se califica de "huida hacia valores reales" y provoca el cataclismo económico y la desarticulación del sistema monetario. Al igual que sucede con toda previsión de futuras circunstancias; tales especulaciones pueden ser erradas; cabe se detenga o se reduzca la actividad inflacionaria, resultando los precios diferentes a los precios previstos.

Esa mayor propensión a comprar que materializa la compensación por el alza de precios; afecta, rápidamente y en mayor grado al mercado de préstamos a corto plazo que al mercado de préstamos a largo plazo. Los préstamos a corto plazo registran, primeramente, esa compensación y es sólo después (por la concatenación que existe entre todas las partes del mercado de préstamos) cuando esa compensación se traslada al mercado de préstamos a largo plazo. Sin embargo, también puede suceder que la compensación aparezca en los préstamos a largo plazo con total independencia de lo que acontezca con los préstamos a corto plazo. En un mercado internacional de préstamos dinámico y normal, sucede tal fenómeno: los prestamistas que tienen confianza en el futuro cercano de la moneda nacional; exigen una reducida compensación por préstamos a corto plazo). Sin embargo, el futuro lejano, no es tan halagueño; y por tanto, en los correspondientes préstamos se incluye la compensación por el alza de precios. Consecuentemente los préstamos al gobierno a largo plazo, en moneda nacional, sólo pueden ser colocados si sus condiciones resultan más favorables para el prestamista que las condiciones correspondientes a préstamos pagaderos en moneda extranjera.

Hemos visto el primer motivo por el que esa compensación amortigua, los efectos de las variaciones de origen monetario de la relación monetaria sobre las respectivas prestaciones de los contratantes. Esa compensación se demora con respecto a las reducciones del poder adquisitivo del dinero; pues esa compensación es consecuencia provocada por los efectos posteriores- que las variaciones de dinero inorgánico producen en la estructura de precios. Es al final de prolongada inflación como de 1963-1990, cuando las cosas cambian. Al aparecer el pánico propio de la desarticulación del sistema monetario, al producirse el cataclismo económico; habrá alza exagerada: de precios; y de la compensación positiva por el alza de precios. Ningún interés de mercado, por grande que sea, es suficiente al potencial acreedor cuando piensa en las pérdidas que le ocasionará la creciente baja del poder de compra del 
Marco Teórico de la Incidencia de la Expansión Monetaria en las Tasas de Interés y los Ciclos Económicos Perú 1990-2006

dinero. El potencial acreedor dejará de hacer préstamos, prefiriendo invertir su dinero en bienes "reales". El mercado de préstamos se paraliza, como en 1988-1990.

\section{EL MARCO TEÓRICO}

Existe una serie de Marcos Teóricos que evalúa la incidencia de la expansión monetaria en las tasas de interés y los ciclos económicos, pero que al basarse en el supuesto de que el interés y la expansión monetaria varían proporcional y simultáneamente y el supuesto que considera el valor como una cualidad objetiva, intrínseca, inherente a las cosas, por lo que la gente compra y vende, única y exclusivamente, por cuanto da igual valor a lo que entrega y a lo que recibe; no permiten ver en su exacta dimensión la incidencia de la expansión monetaria en las tasas de interés y los ciclos económicos de las economías, en especial de la economía peruana. Estos marcos teóricos fueron dise ados por economistas peruanos de renombre como runo Moll "La Moneda 1944" y extranjeros como Jhon Maynard eynes "Teoría General del empleo, interés y el dinero 1936" y Milton Friedman "Políticas monetarias de estabilización 1970".

Así, el fundamento teórico del Presente trabajo se obtiene a partir de las investigaciones teóricas de Fritz Dubois "La economía financiera peruana 1995", Lud ig on Mises "Teoría de la tasa de interés 1981" y Friedrich on Hayek "Expansión monetaria y los ciclos económicos 1978" cuyos Marcos Teóricos basados en el supuesto de la no proporcionalidad ni simultaneidad de las variaciones de los intereses y la expansión monetaria y en el supuesto de que el valor es el reflejo del ansia con que la gente aspira las cosas que le apetece, por lo que la gente compra y vende, única y exclusivamente, por cuanto valoran en menos lo que dan que lo que reciben; permiten ver en su exacta dimensión la incidencia de la expansión monetaria en las tasas de interés y los ciclos económicos, para así diseñar eficaces políticas monetaria y crediticias que den solidez al sector financiero peruano.

\section{PRIMEROS HALLAZGOS}

LA INCIDENCIA DE LA EXPANSIÓN MONETARIA EN LAS TASAS DE INTERÉS DE MERCADO: Las tasas de interés que genera el mercado de préstamos no son uniformes. El componente empresarial contenido en el interés de mercado cambia según las específicas circunstancias de cada operación. na misma tasa de interés del CR tiene desigual valor según el momento en que rija. Son desiguales las circunstancias institucionales que regulan la actividad del CR y la banca privada de cada país, y los respectivos mercados de préstamos; 


\section{Pablo Rivas Santos}

que induce a confusión comparar las correspondientes tasas de interés sin ponderar debidamente las específicas diferencias de cada caso. En el mercado de préstamos prevalece una tendencia a igualar el interés de mercado correspondiente a préstamos de la misma clase en lo relacionado al componente empresarial y la compensación por el alza de precios. Los precios dependen del desigual valor que los consumidores atribuyen a las propiedades físicas de los bienes.

Hay diferencias entre mercado de préstamos a corto plazo (mercado de dinero) y mercado de préstamos a largo plazo (mercado de capitales).

Las diferencias más sobresalientes entre las tasas de interés resultan del componente empresarial del interés de mercado. A tal realidad se refiere la gente cuando dice que el préstamo se basa en la confianza y buena fe.

La conexión entre: todos los sectores del mercado de préstamos; y las tasas de interés determinadas en el mercado de préstamos; se produce por la tendencia del interés originario hacia el final interés originario. En relación con tal tendencia, la teoría monetaria trata el interés de mercado como si fuese un fenómeno uniforme; separando del interés de mercado: el componente empresarial (contenido en el interés de mercado) y la compensación por el alza de precios (a veces contenido en el interés de mercado).

En la economía continuamente se producen nuevos hechos, desviando el movimiento de precios (que tendían hacia un precio final) hacia otro precio final, al cual corresponde un diferente interés originario.

Los empresarios dedicados a reajustar el empleo de factores de producción a los cambios que registran las circunstancias de cada momento, basan sus cálculos en precios e interés que determina el mercado.

Los empresarios se dan cuenta de la aparición de diferencias entre: precios actuales de factores de producción complementarios y el precio previsto del producto final (una vez deducido del precio del producto final el correspondiente interés de mercado) aspirando a beneficiarse con tales diferencias. Es la función que desempeña el interés de mercado en los cálculos del empresario.

\section{El monto del interés de mercado indica al empresario:}

- Hasta qué punto puede desviar factores de producción de la atención de necesidades 
Marco Teórico de la Incidencia de la Expansión Monetaria en las Tasas de Interés y los Ciclos Económicos Perú 1990-2006

temporalmente más cercanas, dedicando esos factores de producción a la atención de necesidades temporalmente más lejanas.

- Cuál será el período de producción que en cada específico caso se ajusta efectivamente al diferente valor que la gente otorga a los bienes presentes con respecto a los bienes futuros.

- No lanzarse a empresas que no se compaginen con las limitadas existencias de bienes de capital efectivamente ahorradas por la gente.

-Ya que puede perturbar esa función del interés de mercado, cobra importancia la propia fuerza impulsora del dinero.

Las variaciones de origen monetario de la relación monetaria (como en 1963-1990) afecta, en determinados casos, al mercado de préstamos antes que a los precios. El aumento de la oferta de dinero inorgánico aumenta la oferta de dinero en el mercado de préstamos, provocando, consecuentemente, alza del interés de mercado, pese a no haber registrado variación el interés originario. En tales supuestos, el interés de mercado se aparta del interés que corresponde a los disponibles bienes de capital; y el interés originario. Entonces el interés de mercado deja de cumplir su función de guiar y orientar las decisiones empresariales, y trastorna los cálculos del empresario, apartando el interés de aquellas vías que mejor permitirían atender las más urgentes necesidades de los consumidores.

Al aumentar la oferta de dinero inorgánico (permaneciendo constantes las restantes circunstancias) provocando una alza de precios; la compensación positiva se incorpora al interés aumentando el interés de mercado. Sin embargo, cuando esos cambios de la relación monetaria afectan al mercado de préstamos; las tasas de interés registran variaciones pero de signo opuesto. Mientras se requiera de una compensación positiva, para reajustar la tasa de interés de mercado a las variadas existencias monetarias; la tasa del interés de mercado baja en sentido opuesto. He aquí un segundo motivo por el cual esa compensación no puede resarcir ni anular los efectos que provocan las variaciones de origen monetario de la relación monetaria; en el contenido de los contratos con pagos aplazados. Porque tal compensación se produce con retraso; la compensación se retrasa tras las ya acontecidas variaciones del poder adquisitivo del dinero. Además, ahora advertimos que, a veces, aparecen fuerzas actuando en sentido opuesto al sentido de la compensación y que surgen incluso antes de que esta compensación tome cuerpo. 


\section{REFERENCIAS BIBLIOGRÁFICAS}

Friedman, Milton. POLÍTICAS MONETARIAS DE ES ESTA ILI ACIÓN. ARGENTINA. Editorial Ateneo. Pag. 310-350. (1960).

Friedman, Milton. MONEDA Y DESARROLLO. ESPA A. Editorial Ateneo. Pag. 123152. (1980).

Friedman Milton. ALANCE DE PAGOS. ARGENTINA. Editorial Ateneo. Pag. 203222. (1970).

Friedman, Milton. N E A REFORM LACIÓN DE LA TEORÍA C ANTITATI A DEL DINERO. ESPA A. Editorial Continental. Primera Edición. Pag. 123-152. (1971). Lucas, Robert. TEORÍA DE LOS CICLOS ECONÓMICOS. ESPA A. Alianza editorial. Pag. 113-152. (1987).

Mundell, Robert A. TEORÍA MONETARIA. ESPA A. Ediciones Amorrurtu Editores. Pag. 323-430. (1971).

Moll Bruno. LA MONEDA. PERÚ. Ediciones Peruanas. 1943.

Mundell, Robert A. y Swoboda, Alexander. PRO LEMAS MONETARIOS DE LA ECONOMÍA INTERNACIONAL. MEXICO D.F. Ediciones Cemla. Pag. 145-190. (1969). 
Keynes, Jhon Maynard, TEORÍA GENERAL DEL EMPLEO, EL INTERÉS Y EL DINERO”. MEXICO. D.F. Fondo de Cultra Económica. 1936.

Rothbard, Murray Newton. MONEDA LI RE Y CONTROLADA. ESPA A. Centro de estudios Sobre la Libertad. Pag. 23-59. (1990).

Von Hayek Friedrich. DESNACIONALI ACIÓN DEL DINERO. ESPA A. Editorial Continental. Pag. 143-187. (1978).

Von Mises Ludwig. TEORÍA DE LA MONEDA Y EL CRÉDITO. ESPA A. Fundación Ignacio illalonga. Pag. 239-452. (1966).

Von Mises Ludwig. ACCIÓN H MANA. ESPA A. Fundación Ignacio illalonga. Pag. $\quad$ 180332. (1980). 